\title{
Rapidly growing cardiac tumour in the right ventricle
}

\author{
Adam Daana Niku, ${ }^{1}$ Will Ryoe Takakura, ${ }^{1}$ Robert Siegel, ${ }^{2}$ Florian Rader $^{2}$
}

${ }^{1}$ Department of Medicine, Cedars-Sinai Health System, Los Angeles, California, USA ${ }^{2}$ Cedars-Sinai Heart Institute, Los Angeles, California, USA

\section{Correspondence to} Dr Adam Daana Niku, adamniku@gmail.com

Accepted 13 August 2018

\section{DESCRIPTION}

A 77-year-old man with a history of Her2 negative, pancytokeratin-positive gastric cancer and synchronous grade 3 a stage 2 a follicular lymphoma (FLIPI score 3 at presentation) treated with chemotherapy was referred for transthoracic echocardiography (TTE) after a CT of the abdomen demonstrated an incidental low-density lesion in the right ventricle (RV) concerning for malignancy or thrombus. There was no mass present on TTE 2 months prior. Repeat TTE (figure 1) demonstrated a large echogenic mass causing right ventricular inflow and outflow tract (RVOT) obstruction. A cardiac MRI (figure 2) confirmed the presence of a heterogeneous mass with adherent superficial thrombus in the RV and extending into the RVOT, consistent in appearance with a tumour. On further review, a PET/CT performed 1 month prior to presentation showed a hypermetabolic node at the RV apex (maximum Standardized Uptake Value 5.7) felt to represent an initial metastatic focus, with no other abnormal hypermetabolic nodes.

Given its rapid growth and the clinical background, suspicion for metastatic malignancy was high. Multiple endomyocardial biopsies could not confirm a tissue diagnosis due to widespread necrosis of the mass; however, the mass was pancytokeratin negative. Suspicion for metastatic lymphoma was high, given its rapid growth and cell marker profile. The patient had multiple elevated lactate dehydrogenase levels coinciding
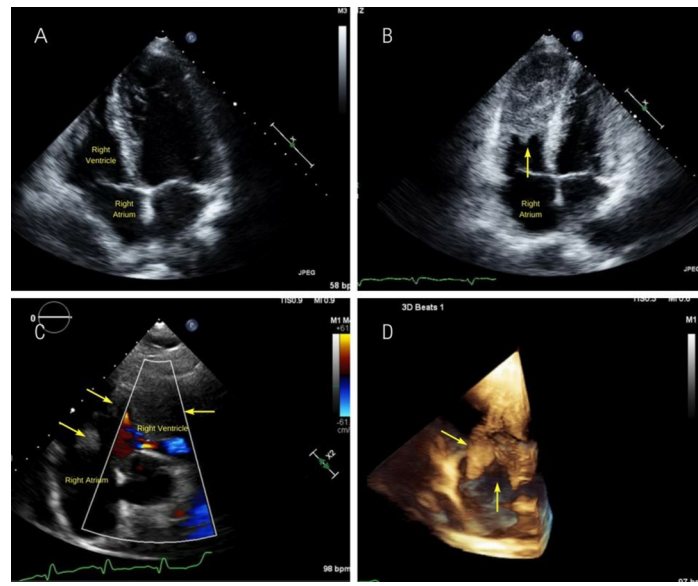

Figure 1 (A) Apical four-chamber view. No visible right ventricular (RV) mass. (B) Apical four-chamber view. Homogenous $6.3 \mathrm{~cm} \times 3.6 \mathrm{~cm}$ mass (borders shown by arrows) in the RV. (C) Parasternal short axis view. RV mass (arrows) obstructing RV outflow tract with colour Doppler showing flow acceleration. (D) Three-dimensional echocardiogram image showing extension of RV mass into right atrium.

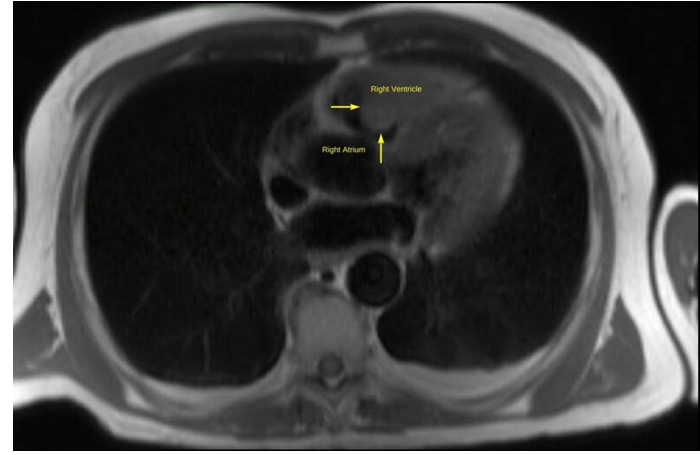

Figure 2 Cardiac MRI, T1-weighted image showing intracavitary right ventricular (RV) mass tumour with extension into RV outflow tract (arrows).

with diagnosis of the mass but never developed B symptoms or laboratory evidence of tumour lysis syndrome. The patient was ultimately admitted to the hospital 3 months after initial discovery of the RV mass with septic shock. Repeat TTE (figure 1) showed continued growth of the mass causing obliteration of the RV with extension into the right atrium and reduction of RV forward stroke volume. The resulting obliteration of the RV cavity resulted in elevated central venous pressure and low cardiac output, causing severe hypotension despite appropriate antibiotics and aggressive fluid resuscitation. Given the size of his RV mass and inability to make a clear diagnosis, his prognosis was considered very poor and he transitioned to do not resuscitate status after discussion. He died 2 days later from cardiopulmonary arrest due to RV failure.

Intracavitary cardiac metastases are considered rare, but studies suggest they may be more common than expected (incidence from $2.3 \%$ to $18.3 \%){ }^{1}$ The patient developed an obstructing RV mass from a small focus in a few months, ultimately leading to death from RV obstruction and loss of forward stroke volume. As is evident in this case, cardiac metastases can grow quite rapidly if not addressed

Learning points

- Secondary cardiac tumours can grow rapidly with serious consequences and should be evaluated, diagnosed and treated early.

- Potential complications of large intracardiac tumours, their recognition on echocardiographic imaging and the possible consequences of such complications.

- Endomyocardial biopsy may not be adequate for the diagnosis of rapidly growing cardiac tumours. 
early. Biopsy alone may be inadequate for diagnosis due to tissue necrosis. Concerning myocardial imaging findings should be promptly evaluated and treated to prevent potentially fatal complications.

Acknowledgements The authors would like to acknowledge Dr Takahiro Shiota for his intellectual input and support in the writing of this article.

Contributors ADN conceived, designed and wrote the initial manuscript. WRT, RS and FR provided intellectual input and revised the final manuscript. ADN is the overall guarantor for the final manuscript.
Funding The authors have not declared a specific grant for this research from any funding agency in the public, commercial or not-for-profit sectors.

Competing interests None declared.

Patient consent Next of kin consent obtained.

Provenance and peer review Not commissioned; externally peer reviewed.

\section{REFERENCE}

1 Bussani R, De-Giorgio F, Abbate A, et al. Cardiac metastases. I Clin Pathol 2007:60:27-34

Copyright 2018 BMJ Publishing Group. All rights reserved. For permission to reuse any of this content visit

http://group.bmj.com/group/rights-licensing/permissions.

BMJ Case Report Fellows may re-use this article for personal use and teaching without any further permission.

Become a Fellow of BMJ Case Reports today and you can:

- Submit as many cases as you like

Enjoy fast sympathetic peer review and rapid publication of accepted articles

- Access all the published articles

Re-use any of the published material for personal use and teaching without further permission

For information on Institutional Fellowships contact consortiasales@bmjgroup.com

Visit casereports.bmj.com for more articles like this and to become a Fellow 